\title{
Contribuições da atividade de estudo para o desenvolvimento da autoria nos escolares ${ }^{1}$
}

\author{
Contributions of learning activity to the development of \\ authorship in students
}

\author{
Érika Christina Kohle $e^{2}$ \\ Stela Miller ${ }^{3}$
}

\section{RESUMO}

$\mathrm{O}$ presente artigo apresenta os resultados de um experimento didático-formativo realizado com crianças de terceiro, quarto e quinto anos do Ensino Fundamental, de um projeto de recuperação e reforço de uma escola da rede estadual de ensino de um município do estado de São Paulo, em situação de criação de escrita de enunciados realizada por meio de atividade de estudo, caminho metodológico escolhido para guiar a prática pedagógica do experimento. $\mathrm{O}$ desenvolvimento dessa atividade objetivou que as crianças se apropriassem do conceito diário pessoal como um gênero de enunciado, por meio de análise, reflexão e planificação mental, desenvolvendo, nessa trajetória, em sua forma ainda incipiente, o pensamento teórico, a criatividade, a autonomia no pensar e no agir, resultando em sua capacidade para produzir seus enunciados de forma autoral. As análises do material gerado durante o experimento foram realizadas com base nos referenciais da Teoria Histórico-Cultural e da Teoria da Atividade de Estudo que forneceram as bases para a compreensão do processo de apropriação e objetivação de conceitos teóricos pelas crianças em suas relações com o objeto de conhecimento e com os sujeitos
\end{abstract}

\begin{abstract}
This article presents the results of a formative-didactic experiment carried out with children of the third, fourth and fifth years of elementary school, of a project for the recovery and reinforcement of a state school in a municipality in the state of São Paulo, in situation of creating written statements through learning activity, methodological path chosen to guide the pedagogical practice of the experiment. The development of this activity aimed at children to appropriate the personal dairy concept as a statement genre, through analysis, reflection and mental planning, developing, in this trajectory, in its still incipient form, theoretical thinking, creativity, autonomy in thinking and acting, resulting in their ability to produce their statements in an authorial way. The analyzes of the material generated during the experiment were carried out based on the references of the HistoricalCultural Theory and the Theory of Learning Activity that provided the basis for the understanding of the process of appropriation and objectification of theoretical concepts by children in their relations with the knowledge object and with social subjects in their environment, aiming at understanding how qualitative changes happen in their psyche. It concludes by affirming learning activity as a
\end{abstract}

${ }^{1}$ Parte de uma pesquisa financiada pela agência de fomento Capes.

2 Doutoranda do Programa de Pós-graduação em Educação da Faculdade de Filosofia e Ciências da Universidade Estadual Paulista - "Júlio de Mesquita Filho" UNESP - Campus de Marília São Paulo, Brasil. ORCID: https://orcid.org/0000-0003-0907-4420. E-mail: erika.kohle@gmail.com. ${ }^{3}$ Professora voluntária - Programa de Pós-graduação em Educação da Faculdade de Filosofia e Ciências da Universidade Estadual Paulista - "Júlio de Mesquita Filho" UNESP - Campus de Marília - São Paulo, Brasil. ORCID: http://orcid.org/0000-0002-3521-9526. E-mail: stelamillercel@gmail.com. 
sociais em seu meio, visando à compreensão de como acontecem as mudanças qualitativas em seu psiquismo. Conclui afirmando a atividade de estudo como um caminho propício ao desenvolvimento da capacidade de autoria em alunos escolares dos anos iniciais do Ensino Fundamental.

Palavras-chave: Educação. Atividade de estudo. Gênero diário pessoal. Capacidade autoral. conducive path to the development of the authorship capacity in school students in the early years of Elementary School.

Keywords: Education. Learning activity. Personal diary genre. Authorial capacity.

\section{Introdução}

Vivemos hoje, ao encerrarmos a segunda década do século XXI, um momento de transformações de ordem política, social, econômica e ideológica que traz nefastas consequências para a educação, bem como para a vida dos trabalhadores e para a defesa dos direitos humanos: o poder central decisório está nas mãos "de uma 'nova direita' que procura combinar o liberalismo econômico [...] com o autoritarismo social" (FREITAS, 2018, p. 13, grifos no original), objetivando "implementar um conjunto de reformas que desestruturam a luta dos trabalhadores e colocam novos marcos de precarização da força de trabalho, ao mesmo tempo que recompõem garantias do processo de acumulação" (FREITAS, 2018, p. 22).

Tudo passa pela lógica do livre mercado. Para a educação, isso se reflete nas demandas para a privatização das escolas públicas, na livre concorrência e na meritocracia para a definição da qualidade das escolas e dos profissionais que nelas trabalham, e na padronização curricular pela via da Base Nacional Comum Curricular e das avaliações feitas em nível nacional.

Em termos de suas finalidades, as propostas para a área de educação, dentro dessa lógica, visam ao preparo do educando para o mercado de trabalho e, ao mesmo tempo, almejam a garantia de que a educação dada esteja dentro dos limites da visão de mundo adotada por seus defensores.

São propostas reducionistas que, sob o manto de um ideário que defende ensino de qualidade, liberdade de escolha da educação pretendida e aprendizagem para todos, 
na verdade produzem a desfiguração das funções da escola, principalmente aquela que se refere à promoção das condições institucionais, curriculares e pedagógicas para a apropriação do conhecimento constituído social e historicamente e, por meio dele, alcançar o desenvolvimento cognitivo, afetivo e moral. (LIBÂNEO, 2020, p. 34).

Impedem, com isso, a possibilidade de as escolas se organizarem de modo a atender adequadamente à sua coletividade, escolhendo os meios mais eficazes, conforme suas peculiaridades, para oferecer um processo de ensino-aprendizagem voltado ao desenvolvimento humano de seus educandos, concretizado pela via da apropriação dos conceitos científicos de todas as áreas do conhecimento e do desenvolvimento de habilidades e capacidades que lhes possibilitam compreender a vida em sociedade, ter chance participar dela e, até mesmo, de transformá-la, agindo crítica, autônoma e criativamente em seu meio.

Embora todas as reformas pensadas e implantadas pelo poder ora instituído mantenham e aprofundem a divisão entre explorados e exploradores, entre os que têm acesso a boas escolas e os que se submetem, sem possibilidade de escolha, à realidade das instituições escolares oficiais, nem sempre dotadas de recursos adequados para seu funcionamento, a prática social gera contradições que põem em cheque a ordem estabelecida e oportunizam a mobilização de forças contrárias, manifestadas por ações democráticas que advêm da necessidade de diminuição das desigualdades sociais. Em todas as instâncias da vida social, em especial no trabalho e nas relações interpessoais, a apropriação de conhecimentos para além daqueles necessários à formação profissional restrita torna-se cada vez mais necessária. A busca desse conhecimento e todos os meios necessários para a sua obtenção passam a ser o conteúdo das reivindicações das camadas sociais mais afetadas por essas reformas: boas escolas para todos, igualdade de acesso a todos os níveis de escolarização, bibliotecas e demais recursos materiais adequados, inclusive os tecnológicos, disponibilizados nos espaços escolares, etc.

No bojo dessas reivindicações, novas propostas para a condução do processo de ensino-aprendizagem dos estudantes eventualmente acabam por 
ser acolhidas pelas escolas como meio de superação do reducionismo imposto à formação discente pelas políticas públicas vinculadas estritamente ao atendimento do mercado de trabalho. Essas escolas cumprem, com isso, seu papel fundamental: levar as crianças a apropriarem-se dos conhecimentos científicos produzidos social e historicamente, e, ao mesmo tempo, ajudá-las a desenvolverem valores cada vez mais humanos com os quais serão capazes de construir sociedades pacíficas e democráticas.

Este artigo traz para a discussão uma dessas propostas, a atividade de estudo, focalizando, especificamente, sua contribuição para o desenvolvimento da autoria de enunciados em alunos escolares dos anos iniciais do Ensino Fundamental, tendo em vista o fato de que as capacidades autorais constituem-se como um instrumento eficaz de inserção das classes menos favorecidas nas instâncias de participação social voltadas à transposição dos filtros sociais de exclusão.

A linguagem escrita, como um instrumento cultural complexo e o mais importante sistema de representação criado pelo homem, ao ser apropriada pelos sujeitos sociais, propicia-lhes o contato com uma gama imensa de produções escritas que foram produzidas ao longo da história e que estão disponibilizadas em variados tipos de suportes, bem como o estabelecimento de relações sociais que estão na base da formação da consciência, que "emerge de relações materiais sociais intrinsecamente vinculadas à constituição da palavra significativa, do signo humano por excelência" (DELARI JUNIOR, 2013, p. 143).

Resulta, pois, crucial o desenvolvimento da capacidade de autoria nos alunos dos anos iniciais do Ensino Fundamental, uma vez que esse aprendizado extrapola os limites da sala de aula: para além de sua formação intelectual, possibilita-lhe participar ativamente da vida social, com consciência de seu papel social, com autonomia para pensar e agir.

\section{Metodologia}

Tendo em vista que a investigação em Ciências Humanas deve analisar os dados a partir dos significados sociais, situados em determinados contextos culturais, a opção metodológica para a condução do trabalho aqui exposto foi o 
experimento didático-formativo, que implica considerar o nível de desenvolvimento real dos sujeitos, as condições dentro das quais podem ser desenvolvidas as atividades de ensino e aprendizagem e o planejamento do trabalho a ser feito em função disso, visando a acompanhar o desenvolvimento de novas formações mentais nesses sujeitos.

$\mathrm{O}$ experimento didático-formativo, adequado às pesquisas do campo pedagógico, tem uma dupla função: ao mesmo tempo em que realiza uma intervenção pedagógica, focalizando experimentalmente um objeto de estudo, acompanha as mudanças qualitativas que ocorrem no psiquismo das crianças por meio dessa intervenção. Constitui-se como uma modalidade do experimento formativo (LIBÂNEO, 2007), também denominado genético-modelador, "que plasma a unidade entre a investigação do desenvolvimento psíquico das crianças e sua educação e ensino" (DAVÍDOV, 1988, p. 196).

O experimento foi realizado com crianças de terceiro, quarto e quinto anos do Ensino Fundamental, de um projeto de recuperação e reforço de uma escola da rede estadual de ensino de um município de médio porte do estado de São Paulo, em situação de criação de escrita de enunciados realizada por meio de atividade de estudo, caminho metodológico escolhido para guiar a prática pedagógica do experimento. O desenvolvimento dessa atividade objetivou que as crianças se apropriassem do conceito diário pessoal como um gênero de enunciado, por meio de análise, reflexão e planificação mental, desenvolvendo, nessa trajetória, em sua forma ainda incipiente, o pensamento teórico, a criatividade, a autonomia no pensar e no agir, resultando em sua capacidade para produzir seus enunciados de forma autoral.

As análises do material gerado durante o experimento foram realizadas com base nos referenciais da Teoria Histórico-Cultural e da Teoria da Atividade de Estudo que forneceram as bases para a compreensão do processo de apropriação e objetivação de conceitos teóricos pelas crianças em suas relações com o objeto de conhecimento e com os sujeitos sociais em seu meio, visando à compreensão de como acontecem as mudanças qualitativas no psiquismo dos escolares. 


\section{Análise dos dados}

Os dados aqui analisados decorrem de uma proposta de trabalho de criação de enunciados determinada pelas necessidades discursivas das crianças, detectadas ao longo de um período de aproximadamente três meses e meio, ao fim do qual elas conseguiram expressar o desejo de relatar acontecimentos que haviam ocorrido consigo mesmas, e, também, as experiências recém acontecidas, contar seus segredos, desejos e anseios e/ou relatar suas projeções para aquele dia ou para aquela semana em que se davam as aulas. Antes disso, ao entrevistarmos as crianças sobre o que gostariam de escrever, falavam mais sobre o que estavam acostumados a fazer na sala de aula regular, ou seja, das expectativas que eram lançadas sobre elas e não propriamente de suas próprias necessidades e expectativas. O tempo decorrido foi, então, necessário para a realização de um trabalho feito com base nas necessidades das crianças.

Com o objetivo de transformar os desejos de expressão das crianças em necessidade comunicativa e em interesse pelo estudo de gênero textual que suprisse as suas necessidades, o diário pessoal foi escolhido pelo coletivo como o primeiro gênero de enunciado a ser trabalhado por meio da atividade de estudo que privilegia os processos de abstração e de generalização, no processo de desenvolvimento do pensamento teórico-científico, por meio de um método que reduz

[...] a diversidade de uma determinada área dos fenômenos da realidade à sua base geradora universal, à essência que é fixada dentro de uma abstração original, com subida subsequente do abstrato para o concreto. O elo central de mediação nesse processo é a abstração teórica (de conteúdo) [...] [que] contém a relação fundamental - geneticamente original - de um objeto estudado refletindo o conteúdo dos potenciais de seu movimento, sua automodificação e seu desdobramento em multiplicidade concreta. (MEDVEDEV \& NEZHNOV, 2018, p. 311, tradução nossa).

Pensada para ser uma proposta transformadora dos sujeitos que a realizam, a atividade de estudo organiza-se com base nos princípios de um ensino que desenvolve, que gera modificações qualitativas no psiquismo dos sujeitos - o Ensino Desenvolvimental (ou Desenvolvente) -, a saber: 1) a atividade de estudo tem como 
base o conteúdo científico produzido historicamente, que é transformado, psicológica e didaticamente, em tarefas de estudo; 2) estas são organizadas em um sistema de ações de estudo conforme situações particulares; 3) os alunos, ao realizarem as tarefas, percorrem um caminho que leva à descoberta das condições sob as quais determinado conceito é visto em sua gênese, aprendendo, pela análise, a buscar a base para seu surgimento; e 4) a atividade de estudo é organizada com base no experimento (é quase-investigativa) por meio do qual conduz o aluno à apropriação de um método de estudo: ele passa do conhecimento abstrato e centrado na totalidade do conteúdo de estudo para o conhecimento específico e elaborado mentalmente, tendo, com isso, uma compreensão das múltiplas determinações do objeto em sua existência (MAGKAEV, 2018).

Para a concretização da atividade de estudo com o gênero de enunciado diário pessoal, elaboramos uma tarefa de estudo cujo conteúdo seria o conhecimento teórico desse gênero, para as crianças criarem sua própria página de diário a partir da consciência cognitiva de sua essência, que seria encontrada, por meio da primeira ação de estudo, com a realização da análise de obras contendo páginas de diário, visando à abstração substancial de sua célula mater - que não só está presente em todas as manifestações desse gênero, mas também deu a origem a esse gênero discursivo, como veremos a seguir.

\section{1 A primeira ação de estudo: abstração substancial}

A partir do estabelecimento do desafio - elaborar uma página de diário pessoal para contar algo sobre si mesmo - demos início à primeira ação de estudo, propondo às crianças a análise do material fático sobre o assunto, com o objetivo de distinguir a relação essencial geneticamente original desse sistema particular de objeto, com o qual estabelecemos interação com o outro, nesse caso, o próprio sujeito. Iniciamos essa análise, feita coletivamente, com dois livros de Doreen Cronin: "Diário de uma Aranha” (CRONIN, 2008) e "Diário de uma minhoca" (CRONIN, 2010).

Essa primeira ação dá início a um trabalho de análise de enunciados do gênero diário pessoal, visando ao domínio, pelas crianças, ao longo da 
atividade, de um método generalizado de ação, que é "a principal forma da atividade subjetiva teórica que dá origem a neoformações psicológicas essenciais na forma de necessidades e capacidades específicas, conhecimento e interesses, relações e inter-relações" (MAGKAEV, 2018, p. 297, tradução nossa), que conduzem à capacidade de autodesenvolvimento necessário à relação ativa da criança com seu meio e consigo própria.

Dada a existência de um só exemplar de cada obra selecionada, o pesquisador deu início à primeira ação de estudo pela oralização do enunciado em foco, à medida que mostrava as imagens correspondentes a ele em cada página. Em seguida, foi realizado um diálogo visando à busca da compreensão das características internas desse gênero discursivo por meio da análise do conteúdo dos enunciados e do modo como foram organizados em sua unidade. Foram focalizados também os aspectos relativos à função social desse gênero. Parte do diálogo estabelecido após a leitura do "Diário de uma minhoca" segue abaixo:

Pesquisadora 1: - O que descobrimos sobre o Minhoca?

Mariana: - Que ele comeu a tarefa.

[...]

Igor: - Ele tem uma irmã.

Tina: - Ele tentou ensinar o Aranha a cavar.

Kátia: - Ele aprendeu a falar oi para as formigas com seu avô.

Igor: - Ele e o Aranha se divertem muito.

Pesquisadora 1: - Por qual motivo o Minhoca escreveu seu diário? O que vocês acham?

Lucas: - Para contar as coisas que ele fez.

Kevin: - Para guardar segredo.

Mariana: - Para relembrar quando ele fez as coisas.

Pesquisadora 1 - Vocês acham que foi importante para a vida dele escrever esse diário? Por quê?

Lucas: - Foi, para ele saber.

Mariana: - Sim, para ele conseguir saber em que dia ele fez cada coisa. (Diálogo de 26/03/2019)

Na sequência, prosseguindo com o objetivo de levar as crianças a distinguirem entre o que é e o que não é essencial no gênero diário e se conscientizarem dos conteúdos que podem compor a sua essência, fizemos a proposta de leitura de uma 
página do Diário de Anne Frank (2014), que traz as memórias de uma menina cuja história trágica criou nelas a necessidade de conhecer um pouco de sua vida e motivou-as a querer ler o relato feito por ela em seu diário.

Como qualquer atividade humana, a atividade de estudo supõe, como ponto de partida, a necessidade de apropriação de certo objeto que a satisfaça. Encontrado o objeto, ele se transforma no motivo e no objetivo da atividade da criança, efetivada por meio de um conjunto de ações e operações dentro das condições dadas pela tarefa de estudo (LEONTIEV, 1988).

Em meio às relações entre esses elementos que estruturam a atividade de estudo, as crianças envolveram-se na ação de discernir entre as diferentes partes que compõem a totalidade do objeto, trabalhando com ele ainda no plano sensível, com o concreto real, material, para chegar a uma primeira abstração substancial, em um movimento de redução dos dados materiais ao plano das ideias, imprescindível para o movimento que se inicia, daí por diante, de ascensão do abstrato ao concreto pensado que leva à formação do pensamento teórico, em conceitos.

O surgimento de concepções ideais no pensamento das crianças muda fundamentalmente sua atitude em relação ao mundo circundante. Os objetos idealizados começam a cumprir a função de conhecimento dos objetos reais. Equipado com esta ferramenta para conhecer a realidade, o pensamento individual torna-se genuinamente reflexivo. (MAGKAEV, 2018, p. 301, tradução nossa).

Por trazer à consciência das crianças a relação universal do objeto que se reflete no correspondente conceito teórico (DAVIDOV, 1988), a primeira ação de estudo, que pode ser considerada a principal, conduz o processo inicial de formação da capacidade de agir sobre os objetos no plano mental, propiciando o surgimento das concepções ideais no pensamento da criança. O diálogo a seguir mostra parte do processo experienciado pelas crianças:

Igor: - Já encontrei a data, aqui, catorze de junho...

Pesquisadora 1:- Tem alguém que encontrou mais alguma parte?

Mariana: - Não tem assinatura.

Pesquisadora 1: - Isso mesmo. Tem despedida, crianças?

Tina: - Sim.

Pesquisadora 1: - Onde está a despedida? 
Tina: - Aqui embaixo.

Pesquisadora 1: - Isso mesmo. "Até logo..." é despedida, não é?

Crianças: - Sim.

Pesquisadora 1: - Alguém encontrou algum vocativo, chamando o diário, falando com o diário como o Aranha e o Minhoca falavam "Querido diário". Tem aí?

Igor: - Não.

Mariana: - Não, nesse não tem.

Pesquisadora 1: - Isso mesmo. Nessa página de diário não tem. O que mais que tem?

Lucas: - O que ela fez no dia do aniversário dela.

Pesquisadora 1: - E como se chama essa parte em que ela conta sobre o aniversário dela, sobre os presentes que ganhou etc.?

Mariana: - Desenvolvimento?

Pesquisadora 1: - Sim. Nele estão os acontecimentos da vida da pessoa que escreve o diário, seus pensamentos sobre as coisas e seus segredos...

[...]

Pesquisadora 1: - O que Anne conta no desenvolvimento?

Lucas: - Dos presentes que ela ganhou no aniversário dela.

Pesquisadora 1: -Isso mesmo. O que mais ela conta para o diário?

Mariana: - Que ela levou o que sobrou para escola e deu para seus amigos.

[...]

(Diálogo de 02/04/2019)

Após as crianças tomarem consciência de que a página de diário é composta de certos elementos de contextualização e um núcleo central que contém as informações constituidoras do relato do autor, nomeado como desenvolvimento, propusemos a análise do desenvolvimento da página do Diário de Anne Frank, anteriormente lida, com enfoque em seu conteúdo. Até esse momento, as crianças já tinham percebido que no desenvolvimento da página de um diário pode haver opiniões de quem o escreve e fatos que ocorreram com essa pessoa. Iniciamos o trabalho solicitando às crianças que selecionassem apenas os fatos ocorridos com Anne e relatados por ela em sua página de diário.

Pesquisadora 1: - Percebemos que o desenvolvimento é a parte mais importante do diário, por isso, agora, o que vocês acham de estudarmos apenas o desenvolvimento da página do diário de Anne Frank?

Mariana: - Tá bom. 
Lucas: - O que tem que fazer?

Pesquisadora 1: - Vamos pensar no que tem apenas no desenvolvimento. Está bem?

Lucas: - Sim

Mariana: Ela conta que achou a festa de seu aniversário divertida

Igor: - Ela ganhou presente.

Kátia: - Que sua festa de aniversário foi divertida.

Tina: - Com seus amigos.

Lucas: - Viu o filme do cachorro.

Pesquisadora 1: - Esses são os fatos relatados por ela. Em duplas, vamos marcar no texto os fatos que ela contou e depois vamos falar para a sala.

(Diálogo de 02/04/2019)

Na sequência das discussões, as crianças demonstraram conseguir discriminar entre fatos relatados no diário, opiniões emitidas por sua autora, aspirações secretas, desejos, que compõem a totalidade da expressão subjetiva própria de um enunciado como o diário. Até esse momento, elas detectaram, então, a ideia geral que organiza esse gênero discursivo, cumprindo, assim, com o objetivo que dirige a primeira ação de estudo, que prevê a apropriação da célula de determinado objeto de estudo, ou seja, a apropriação de uma abstração substancial inicial que "[...] contém em si as potências do todo, e, ao mesmo tempo, se reproduz de novo por esse todo como sua base geral" (DAVÝDOV, 1981, p. 340, tradução nossa). Sobre essa base, as crianças passaram à segunda ação de estudo - a modelação.

\subsection{Segunda ação de estudo: modelação}

A segunda ação de estudo "consiste na modelação em forma objetal, gráfica ou com letras da relação universal” (DAVIDOV, 1988, p. 182) encontrada pelos educandos durante a primeira ação de estudo. Os modelos produzidos durante esse momento da atividade "constituem o elo internamente imprescindível no processo de assimilação dos conhecimentos teóricos e dos procedimentos generalizados de ação" (DAVIDOV, 1988, p. 182).

No modelo estão contidas as propriedades internas do objeto de estudo que não podem ser observadas diretamente no material concreto sensível utilizado no ponto de partida da atividade. Nesse momento, os estudantes lidam com signos, analisando o material de estudo por meio de ações mentais e 
conseguem, então, uma representação esquemática, de caráter geral e essencial, da estrutura real do objeto.

O encaminhamento para a elaboração do modelo simplificado e esquematizado do objeto de estudo foi feito por meio de discussão coletiva, que é o modo de interação pelo qual inicia-se o processo de formação de todas as funções psicológicas superiores, como a formação de conceitos, a atenção voluntária e o desenvolvimento da vontade. "Ao princípio, as funções, no ambiente coletivo, se estruturam na forma de relações entre as crianças, passando logo a ser funções psíquicas da personalidade” (VYGOTSKI, 2000, p. 152), constituindo, nesse processo, sua capacidade de reflexão, uma das neoformações características da atividade de estudo. Parte do diálogo estabelecido com as crianças segue abaixo.

Pesquisadora 1: - Então vamos fazer um quadro aqui na lousa com o que pode ter no desenvolvimento. Está bem?

Crianças: - Sim.

Pesquisadora 1: - Vocês disseram que as pessoas contam coisas que aconteceram com elas. Isso a gente chama de fatos ou de acontecimentos. $\mathrm{O}$ que tem em maior quantidade no desenvolvimento?

Lucas: - Tem segredos.

Igor: - Tem opiniões.

Pesquisadora 1: - A pessoa pode dizer do que ela gosta?

Crianças: - Sim.

Tina: - Escrever de quem ela gosta.

Pesquisadora 1: - Isso mesmo. Ela pode contar como são as pessoas e como elas se comportaram?

Lucas: - Pode.

Pesquisadora 1: - Em um diário pode ter relato de diálogos entre pessoas?

Lucas: - Não.

Crianças: - Sim.

Pesquisadora 1: - Não pode contar o que as pessoas disseram?

Lucas: - Pode.

Pesquisadora 1: - Não apareceu o que o pai da Anne falou para ela no diário?

Mariana: - Apareceu sim.

Pesquisadora 1: - O que ela sentiu?

Mariana: - Medo de se esconder.

Pesquisadora 1: - Pode colocar os sentimentos no diário?

Kevin: - Sim. Ela coloca de quem ela gosta. (Apontando para Kátia.) 
Kátia: - Fica quieto! (Demonstrando muita timidez)

Pesquisadora 1: - Vamos ver o que a Pesquisadora 2 anotou sobre o desenvolvimento no quadro.

(Diálogo de 16/04/2019)

À medida que as crianças se manifestavam, o quadro ia sendo elaborado e registrado na lousa. Segue quadro com as decisões tomadas pelo coletivo da sala para expressar o conteúdo próprio de uma produção de uma página de diário.

\begin{tabular}{|c|c|}
\multicolumn{2}{c|}{ Quadro 1 - Modelo do gênero diário } \\
\hline \multicolumn{2}{|c|}{ DESENVOLVIMENTO DO DIÁRIO (o autor do diário registra:) } \\
\hline - FATOS/ACONTECIMENTOS & - DESEJOS/GOSTOS \\
-OPINIÕES & -ATITUDES \\
- DIÁLOGOS & - SEGREDOS \\
\hline
\end{tabular}

Fonte: Quadro elaborado durante a pesquisa.

Pesquisadora 1: - Nesse quadro da lousa, a Pesquisadora 2 escreveu o que faz parte do desenvolvimento?

Kevin: - Isso. Nós falamos para ela escrever.

Pesquisadora: 1 - Agora, vocês têm um modelo de como pode ser um desenvolvimento.

Lucas: - Então, o desenvolvimento é assim?

Pesquisadora 1: - Isso mesmo. Ele pode ter fatos, opiniões, diálogos, desejos, atitudes, segredos. Entenderam?

Kevin e Lucas: - Sim.

(Diálogo de 16/04/2019)

O quadro acima (Quadro 1) mostra uma forma simples de abstração científica, resultante das ações mentais realizadas pelas crianças sobre o objeto analisado - página de diário pessoal -, que denota o nível de sua apropriação em relação a esse objeto, em termos da compreensão de sua essência.

O modelo elaborado não só serve como a representação da célula do conhecimento teórico objeto de estudo, mas também como uma ferramenta transformadora das ações das crianças sobre o material sensível - o próprio texto - em ações mais complexas realizadas no plano mental, por meio de abstrações, criando nelas, consequentemente, capacidades mais elaboradas tanto para agir sobre novos objetos de conhecimento quanto para refletir sobre eles. 


\subsection{Terceira ação de estudo: transformação do modelo}

A terceira ação de estudo - transformação do modelo - é realizada "com o fim de estudar a propriedade da relação universal do objeto que foi diferenciada" (DAVÍDOV, 1988, p. 183, tradução nossa) no início da atividade. A transformação e a reconstrução do modelo permitem que as crianças estudem as propriedades da abstração essencial da relação universal. "A orientação dos escolares para a relação universal do objeto integral estudado serve de base para formar neles certo procedimento geral destinado a resolver a tarefa de estudo e assim formar o conceito sobre a ‘célula' inicial desse objeto" (DAVÍDOV, 1988, p. 183, tradução nossa).

Para a realização dessa ação de estudo, propusemos a leitura de uma página de diário alterada em sua construção composicional (BAKHTIN, 2003) pela inserção de um trecho de um conto de fadas e um trecho de uma receita culinária. Temas como esses podem ser incluídos em diários, porém conformando, em relação às outras partes do relato, uma totalidade de organização e significação, diferentemente da proposta apresentada às crianças.

Após leitura da página de diário, pedimos para as crianças analisarem a página separando, inicialmente, os fatos relatados pela autora, protagonizando o seguinte diálogo:

Pesquisadora 1: - Quantas coisas que aconteceram com ela? Marque apenas os fatos. Tá bem?

Crianças: - Tá.

Pesquisadora 1: - Vamos contar quais foram os fatos que a menina relatou ao seu diário?

Crianças: - Sim

Lucas: - Eles vão cuidar do primo.

Kevin: - Essa parte aqui não é.

Pesquisadora 1: - Não é o quê?

Kevin: - De diário, porque tem rei, princesa, essas coisas...

Mariana: - No final tem uma receita.

[...]

Pesquisadora 1: - Realmente, esses trechos não são de diário.

Mariana: - É da princesa e da ervilha, a gente leu no começo do ano.

(Diálogo de 07/05/2019) 
Com a mesma estratégia de inserção de trechos que quebravam a noção de totalidade do gênero do enunciado em estudo, foi pedido às crianças que colocassem em ordem uma página de diário que estava dividida em pequenas partes semelhantes em extensão. Nessa página, inserimos, da mesma forma que fizemos com o texto anterior, um trecho de um conto de fadas e um trecho de uma receita culinária, que elas deveriam retirar durante a montagem da página de diário com que trabalhavam naquele momento. Segue parte do diálogo que mostra as tomadas de decisões de duas crianças.

Mariana: - Separei esses aqui.

Pesquisadora 1: - Por que você separou estas partes aqui?

Mariana: - Nestes aqui, eu acho que tem pegadinha.

Pesquisadora 1: - Explica isso melhor para mim.

Kátia: - A gente acha que não faz parte do diário.

Pesquisadora 1: - Vocês acham isso por quê?

Mariana: - Sabe por quê? Porque eu acho que estes trechos não seriam do diário.

Pesquisadora 1: - Você tem que montar toda a página para confirmar essa hipótese, para ver se esses trechos não se encaixam em nenhuma parte do diário.

Mariana: - Essa aqui eu tenho quase certeza. Olha! Então ficaram com a certeza de terem encontrado uma princesa verdadeira. [...]

Pesquisadora 2: - Tem mais algum trecho?

Mariana: Essa parte aqui é de uma receita de bolo. Olha só: Depois espalhe sobre o bolo ainda quente e quando esfriar vai formar uma casquinha.

Pesquisadora 1: - Ela leu junto com você?

Mariana: - Sim.

Pesquisadora 1: - Vocês estão certas.

(Diálogo de 07/05/2019)

$\mathrm{Na}$ relação entre manifestações do não-objeto e as que caracterizam substancialmente o objeto em estudo, as crianças vão se apropriando das propriedades internas que caracterizam a essência desse objeto, e, por esse meio, apropriam-se do conhecimento teórico do objeto que implica a sua abstração original, a elaboração de modelo que a represente e as possíveis transformações desse modelo, em um processo que integra a assimilação do conteúdo do objeto de estudo, o método para descobrir sua célula essencial e 
as possibilidades de transformá-la na busca pela superação do conhecimento superficial do objeto.

Nesse processo, as crianças são levadas a realizar condutas analíticosintéticas que, ao final, resultarão na formação do conceito. O diálogo a seguir mostra um momento em que a ação docente visava a buscar com elas uma síntese do conteúdo trabalhado até então.

Pesquisadora 1: - Vocês já entenderam quais são as partes do diário e o mais importante que é o que tem no desenvolvimento. $\mathrm{O}$ que pode ter no desenvolvimento?

Lucas: - Não sei.

Tina: - Um fato.

Igor: - Opiniões.

Pesquisadora 1: Fatos acontecidos ou que ainda estão acontecendo?

Lucas: - Acontecidos.

Pesquisadora 1: - Aqui, no diário, ela não relata o que estava acontecendo naquele momento?

Lucas: - É.

Pesquisadora 1: - Então, podem ser os dois. Fatos que aconteceram e fatos que estão acontecendo. A Anne conta um fato do passado que ela havia jogado pingue-pongue e tomado muito sorvete e um fato de seu presente que todos haviam saído de sua casa naquele momento. O que mais eu posso colocar no desenvolvimento do diário, além das opiniões e dos fatos?

Igor: - Diálogo.

[...]

Pesquisadora 1: - E na parte do diário de Anne Frank não tinha um diálogo?

Crianças: - Sim.

Luan: - Ela perguntava quando eles tinham que mudar.

Pesquisadora 1: - Para quem?

Lucas: - Para o papai dela.

Pesquisadora 1: - Sim. Eles teriam que se esconder. Assim, a gente viu que o desenvolvimento é parte em que...?

Mariana: - A pessoa conta o que fez.

Pesquisadora 1: - Isso mesmo. As coisas que acontecem ou que aconteceram são relatadas.

Kátia: - Conta os segredos.

Pesquisadora 1: - Exato. E o que mais?

Igor: - Fala as opiniões.

Pesquisadora 1: - Então, conforme vocês disseram, no diário contamos as coisas que aconteceram, dizemos o que estamos sentindo, damos nossas opiniões. É isso? 
Crianças: - É.

(Diálogo de 14/05/2019)

O movimento da análise à síntese compreende o processo que leva à visão da totalidade do objeto de estudo: pela análise, as crianças chegam à compreensão dos elementos, das propriedades e das relações que caracterizam o objeto de estudo, e, pela síntese, obtêm a junção dos elementos que haviam sido identificados no processo de análise do objeto de conhecimento (PETROVSKI, 1980). Para a expressão dessa síntese, pedimos às crianças que elaborassem uma explicação para o conceito formado para diário pessoal. A solicitação foi feita no diálogo transcrito a seguir.

Pesquisadora 1: - Em nosso estudo sobre a página de diário, o que percebemos?

Lucas: - Tem que ter o desenvolvimento.

Pesquisadora 1: - Isso, o desenvolvimento é o mais importante. Nele, as coisas que aconteceram são relatadas, os sentimentos e as opiniões são ditos. O que mais?

Mariana: - Podemos contar o que estamos pensando.

Pesquisadora 1: - Agora, eu tenho um desafio para vocês. Nesta folhinha aqui, vocês vão me responder - o que é um diário para vocês. Cada um vai responder a sua.

(Diálogo de 07/05/2019)

Quadro 3 - Explicação para conceito de diário pessoal

\begin{tabular}{|c|}
\hline Um diário pessoal é... \\
\hline
\end{tabular}

Fonte: registros das pesquisadoras.

Seguem abaixo as explicações dadas para o conceito de diário pessoal por duas crianças:

Figura 1 - Explicação de Tina para o conceito de diário pessoal

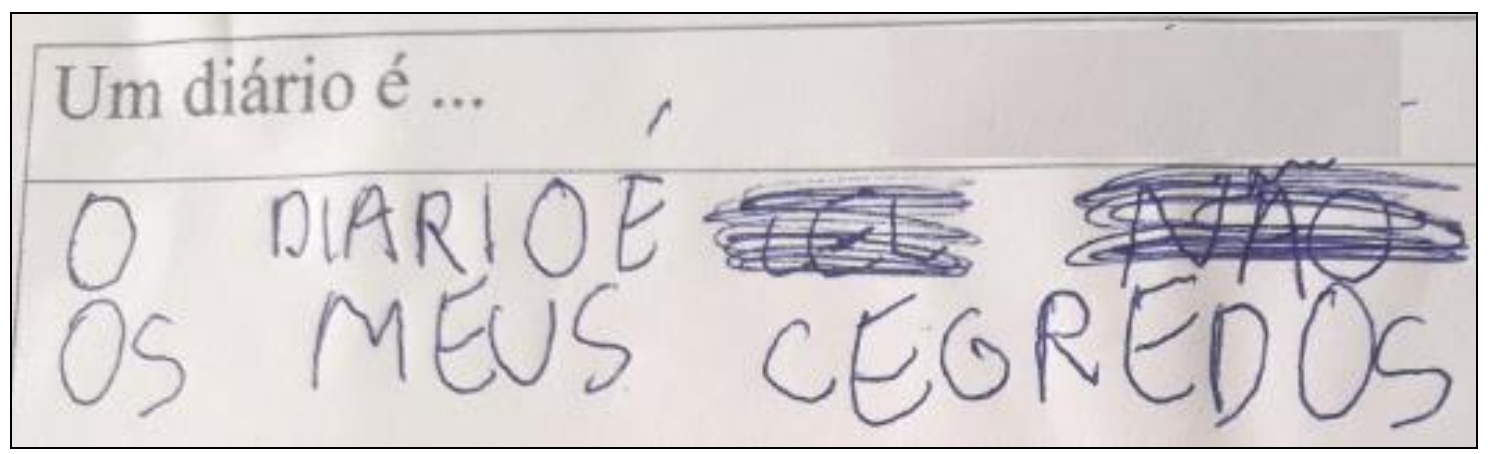

Fonte: registros das pesquisadoras. 
Figura 2 - Explicação de Kátia para o conceito de diário pessoal

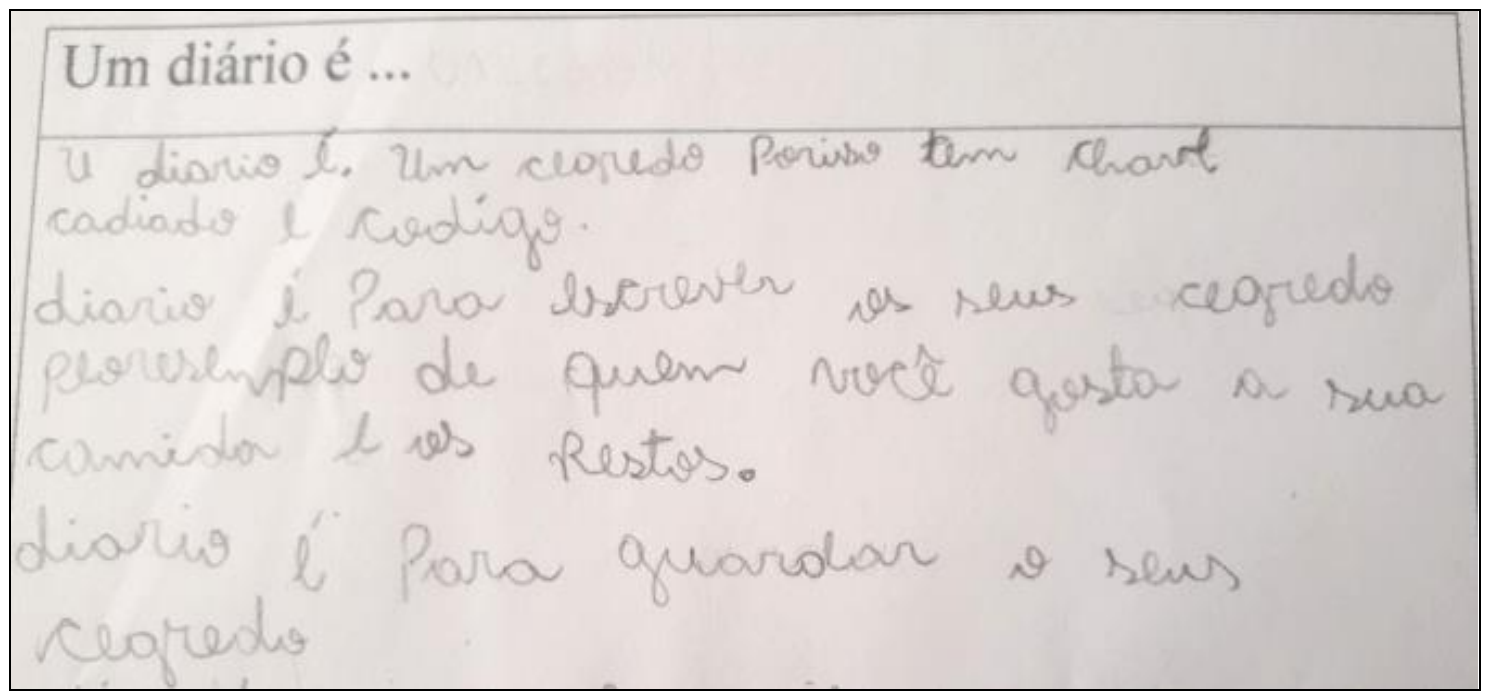

Fonte: registros das pesquisadoras.

A culminância desse processo foi atingida na ação de estudo subsequente, durante a qual as crianças escreveram seus próprios enunciados do gênero estudado, tendo em vista seus desejos e necessidades de escrita, exercitando sua capacidade criadora autônoma para produzir, à sua maneira, as páginas de um diário pessoal, uma tarefa particular que reflete um aspecto essencial da atividade de estudo: sua ligação com o desenvolvimento do pensamento produtivo, ou criador, dos escolares.

\subsection{Quarta ação de estudo: objetivação do objeto/fenômeno de estudo}

Por meio da quarta ação de estudo as crianças "concretizam a tarefa de estudo inicial e a convertem na diversidade de tarefas particulares que podem ser resolvidas por um procedimento único (geral), assimilado durante a realização das anteriores ações de estudo" (DAVÍDOV, 1988, p. 183, tradução nossa), que, no caso em análise, foi a escrita de uma página de diário pessoal com fatos acontecidos em suas vidas e que gostariam de relatar.

Durante o processo de produção dos enunciados, as crianças, em sua maioria, mostravam-se concentradas no que estavam fazendo, fornecendo, com isso, indícios de que estavam inseridas na atividade e que expressar algo sobre si mesmas tinha um sentido positivo para elas. Evidência disso pode 
ser encontrada no conteúdo dos relatos de duas crianças que expressaram fatos de importância vital para elas: Tina revela um problema pessoal que a afeta, e Mariana relata o valor que tem em sua vida a participação em projeto mantido pela escola.

As produções finais revelam a objetivação das crianças a partir da apropriação que fizeram do conteúdo das ações desenvolvidas durante a atividade de estudo. Embora a maioria das crianças tenha compreendido o gênero discursivo diário pessoal em sua essência, elas se achavam em níveis distintos de domínio do conhecimento linguístico necessário à organização do enunciado, como se pode notar pelos enunciados que aparecem nas Figuras 4 e 5. Seguem as produções.

Figura 4 - Versão final da página de diário pessoal de Tina

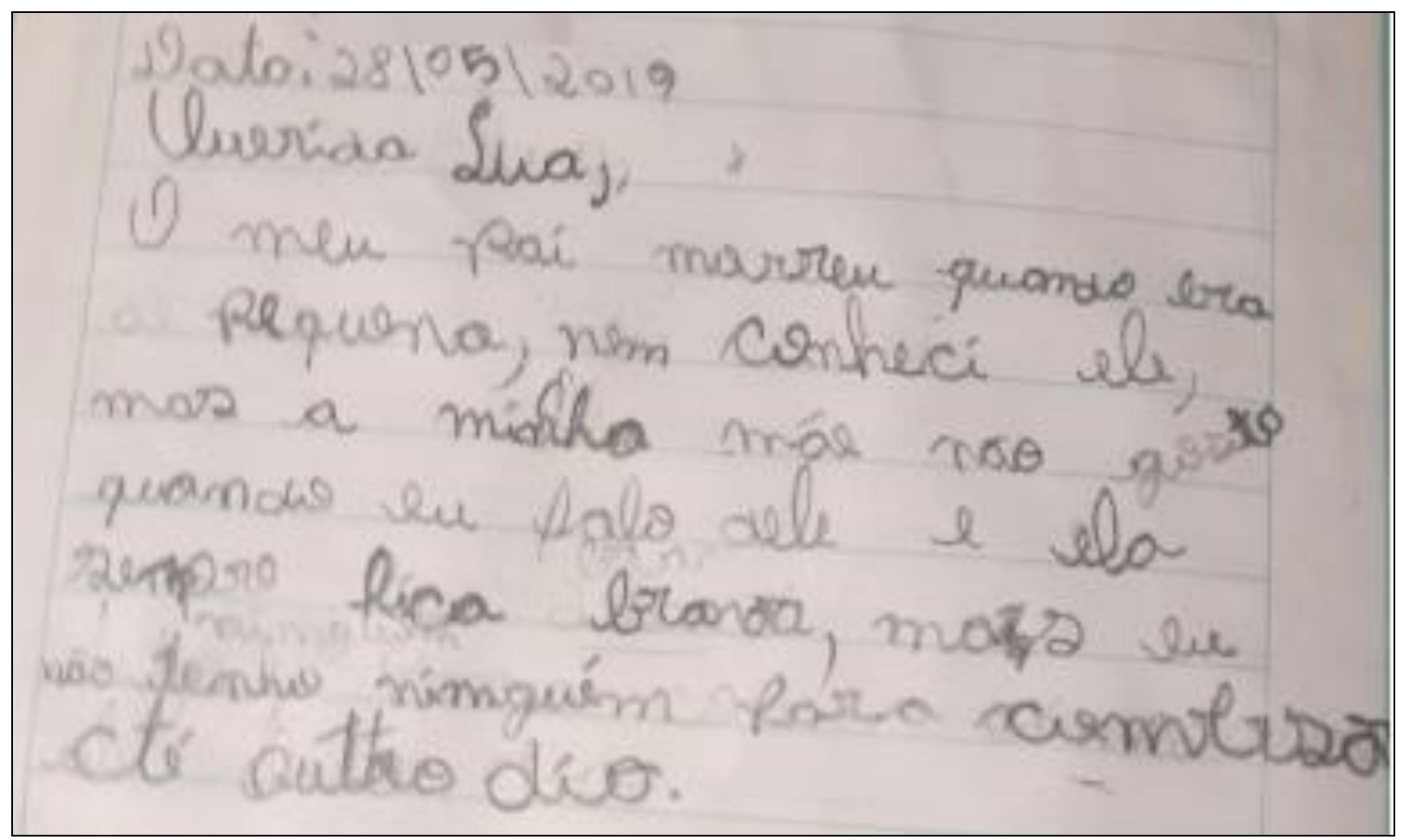

Fonte: registros das pesquisadoras 
Figura 5 - Versão final da página de diário pessoal de Mariana

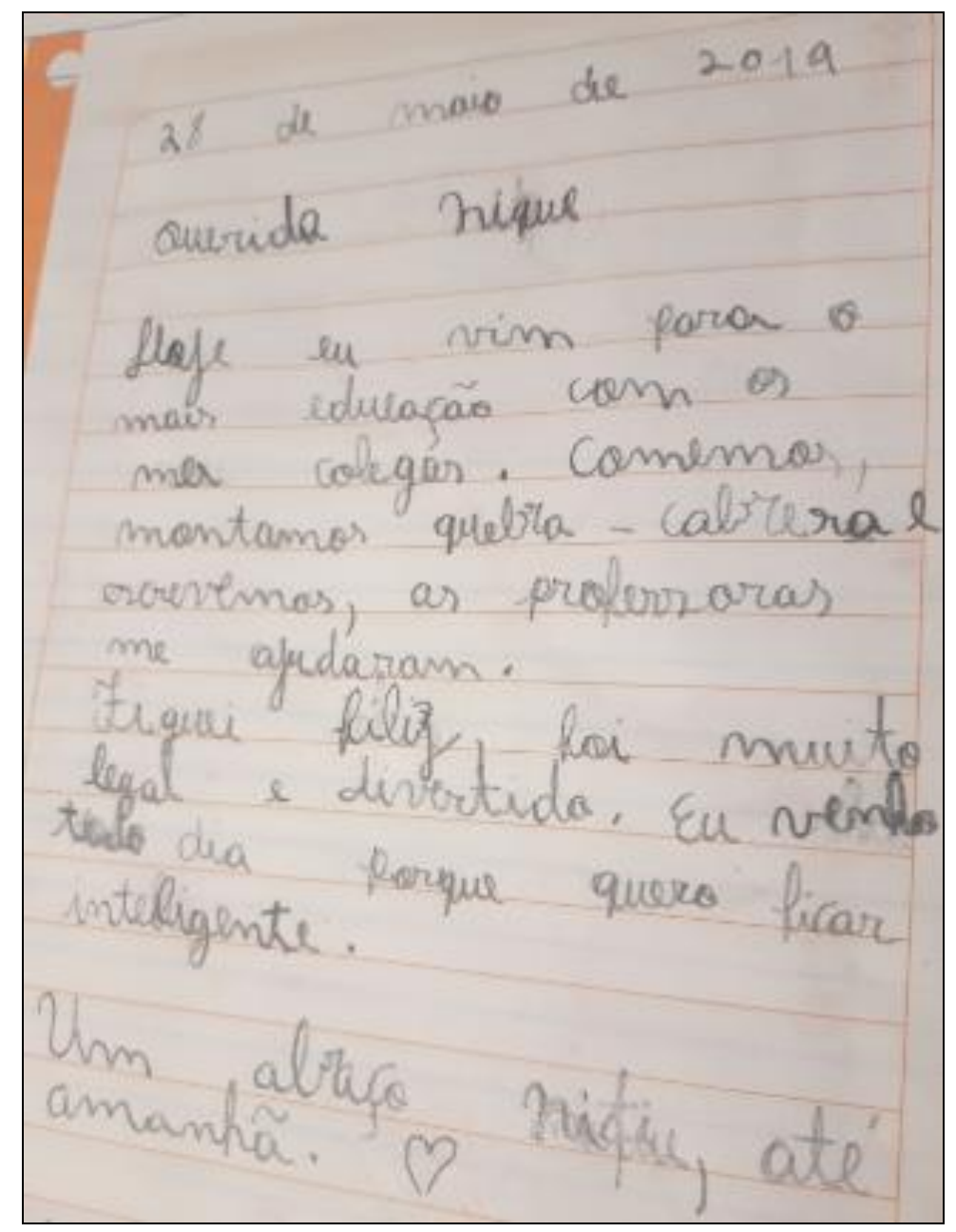

Fonte: registros das pesquisadoras.

Apesar disso, durante o processo de desenvolvimento da atividade de estudo, todos participavam das discussões, expressando suas ideias, seus sentimentos, conteúdos de sua subjetividade que se encontram integrados àqueles das ações exercidas sobre o objeto de estudo formando uma unidade do cognitivo e do afetivo na formação do sujeito autor: as crianças adquirem conhecimento, desenvolvem habilidades a eles relacionadas e capacidades que lhes possibilitam, ao longo do tempo, pensar criativamente os conteúdos de suas tarefas de estudo e agir com autonomia em relação aos procedimentos a serem adotados para a resolução de novas situações de aprendizagem, configurando, com isso, sua capacidade de autoria. 


\subsection{Quinta ação de estudo: controle}

A ação de controle destina-se a "estabelecer a correspondência da composição operacional da ação com as condições essenciais de sua realização" (DAVÍDOV, 1988, p. 231, tradução nossa), tendo como base a reflexão que propicia à criança o exame dos fundamentos das ações que realiza, objetivando assegurar que o procedimento geral assimilado tenha todas as operações necessárias à resolução de tarefas concretas particulares.

Essa é uma ação que, para ser realizada, mobiliza a capacidade de reflexão da criança, uma vez que está em jogo pensar sobre o procedimento que utiliza para realizar sua própria ação. No experimento, ela se desenvolveu por meio de diálogo entre o pesquisador e cada criança, durante o processo de produção de uma página de diário pessoal, pelo qual aquele exerce a função do par mais experiente que atua na zona de desenvolvimento proximal desta, onde estão as funções psíquicas superiores ainda em processo de formação, e que permite ao professor "determinar os futuros passos da criança e a dinâmica do seu desenvolvimento e examinar não só o que o desenvolvimento já produziu, mas também o que produzirá no processo de maturação" (VIGOTSKII, 1988, p. 113).

\subsection{Sexta ação de estudo: avaliação}

A avaliação "permite determinar se está assimilado (e em que medida) ou não o procedimento geral de solução da tarefa de estudo dada, se o resultado das ações de estudo corresponde (e em que medida) ou não a seu objetivo final” (DAVÍDOV, 1988, p. 184, tradução nossa).

No experimento realizado, a avaliação se deu por meio da apreciação das páginas de diário das crianças por seus colegas, após decidirem que suas criações seriam lidas apenas pelas pessoas escolhidas por elas, caso quisessem mostrar seu texto a alguém, não apenas para constatar a adequação do escrito ao procedimento de sua produção, mas também para que o endereçamento real da página de diário pessoal fosse percebido pelas crianças - o relato íntimo para si e para seus confidentes. Parte desse processo de decisão está no diálogo a seguir. 
Pesquisadora 1: - Kevin, para quem você vai mostrar seu texto?

Kevin: - Para ela. (apontando para a sua irmã Kátia ao seu lado).

Pesquisadora 1: - Você quer mostrar para mais alguém?

Kevin: - Para ele. (apontando para Igor).

Pesquisadora 1: - Igor, você pode deixar o Kevin ler seu texto?

Igor: - Posso.

Pesquisadora 1: - Então, fica assim - Kevin lê o texto de Igor e Igor lê o texto de Kevin. Pode ser?

Kevin: - Tá.

Igor: - Pode.

[...]

Pesquisadora 1: - Está ótimo. Sentem-se juntos para trocarem as páginas de diário. Agora, vocês poderão ver o que seus amigos fazem e o que relatam sobre seu dia.

(Diálogo de 28/05/2019)

Após lerem as páginas do diário pessoal direcionadas a cada interlocutor, as crianças dialogaram com seus autores e com as pesquisadoras sobre o conteúdo das criações verbais. Estava em jogo o desenvolvimento, nas crianças, de sua capacidade de emitir opiniões, juízos de valor, não apenas sobre produções alheias, mas também sobre suas próprias produções, que são condutas nem sempre estimuladas pela escola em seu afã de transmitir conhecimentos aos alunos, mas que são imprescindíveis para a formação de sujeitos críticos, capazes de expressar suas próprias ideias e de tomar posição diante de fatos, acontecimentos, fenômenos e problemas com que circunstancialmente se defrontam. Segue diálogo estabelecido com um grupo de crianças.

Pesquisadora 1: - Para quem você mostrou sua página de diário, Mariana?

Mariana: - Para as irmãs, para a Kátia.

Pesquisadora 1: - O Lucas já viu seu texto e eu também. Você falou sobre nossos encontros, fico feliz que gosta de vir para cá estudar comigo e com as outras professoras.

Mariana: - Vou mostrar para minha mãe, ela gosta de ver as minhas coisas da escola.

Pesquisadora 1: - Ela vai gostar de saber que também se diverte por aqui.

[...]

Pesquisadora 1: - Meninas, o que acharam do diário da Mariana?

Tauane: - Gostei porque ela falou de nós.

Tina: - Tem o nome legal. (Referência ao nome dado ao diário: Nique)

Pesquisadora 1: - Inspirado no diário de Anne Frank, não foi? 
Mariana: - Sim.

(Diálogo de 28/05/2019)

A ação de avalição encerrou o trabalho que deu início ao processo de formação, nas crianças, da atividade de estudo, que é a atividade principal das crianças em idade escolar, estruturada de modo a desenvolver capacidades novas como análise, síntese, reflexão e ação mental sobre objetos de estudo, conduzindoas, ao longo de um tempo à apropriação de um procedimento de estudo a ser adotado com autonomia e à aquisição de uma nova forma de pensamento, o pensamento teórico, em conceitos, para entender o mundo a sua volta e nele agir de forma criativa, como autores de sua própria vida.

\section{Considerações finais}

O movimento próprio da atividade de estudo, tal como se apresentou ao longo do experimento didático-formativo aqui relatado, revela o potencial dessa atividade como uma ferramenta metodológica apropriada tanto para a condução de pesquisas na área pedagógica, como para a organização do processo de ensinoaprendizagem em sala de aula. Por meio dessa atividade, é possível acompanhar o processo de formação, nas crianças, de novas funções psicológicas superiores como as capacidades relacionadas ao pensamento teórico - análise, síntese, reflexão, abstração, generalização e planificação mental - que demandam, para seu desenvolvimento, um tempo longo de inserção da criança nessa atividade, nas diferentes áreas do conhecimento. Favorece, também, a apropriação, pelas crianças, de conceitos científicos e, nesse processo, desenvolve nelas as capacidades do pensamento teórico acima mencionadas, a criatividade, a autonomia para agir e uma atitude positiva em relação ao conhecimento, mudando qualitativamente cada sujeito da aprendizagem.

O trabalho com a produção textual, tal como foi focalizado no experimento aqui relatado, não abarca todo o conteúdo e toda a complexidade que o processo de formação da atividade de estudo nas crianças exige, porém é uma parte integrante dele e coopera na obtenção do objetivo principal da atividade de estudo, qual seja, o da transformação qualitativa do próprio sujeito que a realiza. 
Parte desse processo transformador é desenvolver na criança a consciência de que a escrita é uma necessidade vital que cumpre funções sociais diferentes conforme as necessidades de interação com o outro (ou para si mesmo, como é o caso do diário pessoal) pela via dessa linguagem. Difere frontalmente da forma como a escola habitualmente considera os escritos das crianças: produções que ficam guardadas em alguma pasta, em algum armário ou em alguma gaveta na escola, cuja única função é ter as capacidades gramaticais dos alunos avaliadas e seus erros ressaltados por meio das correções de seus professores.

As crianças que participaram do experimento, ainda que no início do processo de formação da atividade de estudo, ao longo do cumprimento da tarefa de estudo, conseguiram realizar as ações voltadas à apropriação da essência do gênero discursivo em foco e ao uso de suas capacidades de análise, de abstração, de generalização, de reflexão e de planificação mental. Nesse processo, foi possível para elas revelar essa essência e chegar ao final da atividade objetivando o que foi aprendido no seu transcorrer por meio da criação de enunciados do gênero diário pessoal, o que lhes permitiu avançar o desenvolvimento de suas capacidades autorais na área da linguagem escrita.

O experimento revelou que as crianças se interessam por participar das discussões realizadas pelo coletivo da sala, engajam-se na tarefa de estudo realizando as ações previstas para sua resolução, sentem-se motivadas quando veem um sentido vital para sua atividade, enfim, mostrou que há espaço para a implementação de um trabalho com base no conteúdo científico, no desenvolvimento das capacidades específicas do pensamento teórico, no estímulo à criatividade, na possibilidade de fazer escolhas, dar opiniões e tomar decisões no decorrer do processo de estudo.

A atividade de estudo, sem diminuir o valor da apropriação de conhecimento, dado que seu objeto é o conhecimento científico, projeta como seu objetivo último a transformação qualitativa do próprio sujeito da atividade: novas funções psíquicas vão se formando e reorganizando todo o sistema de funções, originando uma estrutura de funções com uma nova qualidade (VERESOV, 2014). Por essa razão, a ênfase é maior no processo que no produto da atividade, 
porque é no movimento das ações destinadas à apropriação dos conceitos que são formadas as novas capacidades nos sujeitos da aprendizagem.

Tendo isso em vista, podemos afirmar que o processo de ensinoaprendizagem efetivado durante a realização do experimento formativo aqui relatado caracteriza uma proposta de trabalho pedagógico que reflete não apenas um direcionamento para a concretização de um produto final resultante da capacidade autoral da criança para a criação de enunciados - no caso, a elaboração de página de diário pessoal; reflete também, e principalmente, um caminho de desenvolvimento dessa capacidade que, ao longo do processo de formação da atividade de estudo, extrapola os limites do produto conseguido pela criança e vai até o desenvolvimento da capacidade de autoria da sua própria existência.

\section{Referências}

BAKHTIN, M. Estética da criação verbal. São Paulo: Martins Fontes, 2003.

CRONIN, D. Diário de uma Aranha. Ilustrado por Harry Bliss. Rio de Janeiro: Companhia das letrinhas, 2008.

CRONIN, D. Diário de uma Minhoca. Ilustrado por Harry Bliss. Rio de Janeiro: Companhia das letrinhas, 2010.

DAVÍDOV, V. La enseñanza escolar y el desarrollo psíquico. Moscú: Editorial Progreso, 1988.

DAVÝDOV, V. V. Tipos de generalización en la enseñanza. Habana: Editorial Pueblo y Educación, 1981.

DELARI JUNIOR, A. Vigotski: consciência, linguagem e subjetividade. Campinas, SP: Editora Alínea, 2013.

FRANK, A. O diário de Anne Frank. Tradução de Alves Calado. Rio de Janeiro: Record, 2014.

FREITAS, L. C. de. A reforma empresarial da educação - nova direita, velhas ideias. 1. ed. São Paulo: Expressão Popular, 2018.

LEONTIEV, A. N. uma contribuição à teoria do desenvolvimento da psique infantil. In: VIGOTSKII, L. S.; LURIA, A. R.; LEONTIEV, A. N. Linguagem, desenvolvimento e aprendizagem. 4. ed. Tradução Maria da Penha Villalobos. São Paulo: Ícone: Universidade de São Paulo, 1988, p. 59-83. 
LIBÂNEO, J. C. Experimento didático como procedimento de investigação em sala de aula. Texto de uso exclusivo do autor na disciplina "Didática e Ensino Desenvolvimental” do Programa de Pós-Graduação em Educação da Universidade Católica de Goiás, 2007.

LIBÂNEO, J. C. A desfiguração da escola e a imaginação da escola socialmente justa. In: MENDONÇA, S. G. de L. et al (org.). (De)formação na escola: desvios e desafios. Marília: Oficina Universitária; São Paulo: Cultura Acadêmica, 2020.

MAGKAEV, V. KH. Theoretical Premises Underlying the Study and Diagnosis of the Development of Reflective Thinking. In. V.V. DAVYDOV \& V.V. RUBTSOV. Developing Reflective Thinking in the Process of Learning Activity, Journal of Russian \& East European Psychology, 55:4-6, 287-571, 2018. To link to this article: DOI: https://doi.org/10.1080/10610405.2018.1536008.

MEDVEDEV A.M; NEZHNOV P.G. Studying Contentful Analysis as a Component of Reflective Thinking: Methods and Results. In. V.V. DAVYDOV \& V.V. RUBTSOV. Developing Reflective Thinking in the Process of Learning Activity, Journal of Russian \& East European Psychology, 55:4-6, 287-571, 2018. To link to this article: DOI: https://doi.org/10.1080/10610405.2018.1536008.

PETROVSKY, A.V. Psicología General. Moscú: Editorial Progreso, 1980.

VERESOV, N. Refocusing the lens on development: towards genetic research methodology. In: FLEER, M.; RIDGWAY, A. Visual methodologies and digital tools for researching with Young children. New York: Springer, 2014, p. 129-149.

VIGOTSKII, L. S. Aprendizagem e desenvolvimento intelectual na idade escolar. In: VIGOTSKII, L. S.; LURIA, A. R.; LEONTIEV, A. N. Linguagem, desenvolvimento e aprendizagem. 4. ed. Tradução Maria da Penha Villalobos. São Paulo: Ícone: Universidade de São Paulo, 1988, p.103-118.

VYGOTSKI, L. S. Obras escogidas. Tomo III. 2. ed. Madrid: Visor, 2000. 